\title{
Evaluation of Galectin-3 as a Novel Biomarker for Chagas Cardiomyopathy
}

\author{
Márcia Maria Noya-Rabelo ${ }^{a, b}$ Ticiana Ferreira Larocca ${ }^{a, c, d}$ \\ Carolina Thé Macêdo ${ }^{a, c, d}$ Jorge Andion Torreão ${ }^{a, b}$ \\ Bruno Solano de Freitas Souza ${ }^{c, d}$ Juliana Fraga Vasconcelos ${ }^{c, d}$ \\ Luciana Estrella Souza $^{e}$ Agnaluce Moreira Silva ${ }^{e}$ Ricardo Ribeiro dos Santos ${ }^{d}$ \\ Luís Claudio Lemos Correia ${ }^{a, b}$ Milena Botelho Pereira Soares ${ }^{c, d}$ \\ ${ }^{a}$ Department of Cardiology, Hospital São Rafael, ${ }^{b}$ Escola Bahiana de Medicina e Saúde Pública, \\ 'Gonçalo Moniz Research Center, CPqGM-Fiocruz/BA, ${ }^{d}$ Center for Biotechnology and Cell Therapy, and \\ eClinical Diagnostics Laboratory, Hospital São Rafael, Salvador, Brazil
}

\section{Key Words}

Chagas disease $\cdot$ Biomarkers $\cdot$ Galectin-3

\section{Abstract}

Objectives: Chagas cardiomyopathy has worse long-term outcomes than other cardiomyopathies. A biomarker strategy to refer subjects for noninvasive cardiac imaging may help in the early identification of cardiac damage in subjects with Chagas disease. Galectin-3 (Gal-3) is a mediator of cardiac fibrosis shown to be upregulated in animal models of decompensated heart failure. Here we assessed the correlation of Gal-3 with myocardial fibrosis in patients with Chagas disease. Methods: This study comprised 61 subjects with Chagas disease. All subjects underwent clinical assessments, Doppler echocardiography and magnetic resonance imaging. Plasmatic Gal-3 was determined by ELISA. Results: Delayed enhancement (DE) was identified in 37 of 61 subjects (64\%). The total amount of myocardial fibrosis was $9.4 \%$ [interquartile interval (IQI): 2.4-18.4]. No differences were observed in Gal-3 concentration according to the presence or absence of myocardial fibrosis, with a median Gal-3 concen-

\section{KARGER}

๑) 2016 S. Karger AG, Basel

E-Mail karger@karger.com

www.karger.com/crd tration of $11.7 \mathrm{ng} / \mathrm{ml}$ (IQI: 9.4-15) in subjects with DE versus $12.9 \mathrm{ng} / \mathrm{ml}$ (IQI: 9.2-14) in subjects without $\mathrm{DE}(p=0.18)$. No correlation was found between myocardial fibrosis and Gal3 concentration ( $r=0.098 ; p=0.47)$. Conclusions: There is no correlation between the degree of myocardial fibrosis and the concentration of Gal-3 in subjects with Chagas disease.

(c) 2016 S. Karger AG, Basel

\section{Introduction}

The main symptomatic form of Chagas disease is a cardiomyopathy characterized by heart failure, ventricular arrhythmias, heart blocks, thromboembolic events and sudden death [1]. Previous studies demonstrated that subjects with Chagas disease cardiomyopathy have worse long-term outcomes than subjects with cardiomyopathy due to other etiologies [2]. The worst prognosis has been

The authors take responsibility for all aspects of the reliability and freedom from bias of the data presented and their discussed interpretation. 
attributed to the continuous myocardial damage due to parasite persistence and immune-mediated mechanisms, leading to interstitial fibrosis throughout the myocardium [3]. Cost-effective strategies to identify subgroups of subjects with progressive fibrosis before the occurrence of extensive remodeling are of great interest.

There is a need to find new biomarkers that may reflect the pathophysiological mechanisms of myocardial fibrosis, in order to support the risk stratification, especially regarding subjects with Chagas disease, thus allowing the application of potentially invasive and expensive therapies to those who are most likely to benefit. To date there are no biomarkers accurate enough to predict myocardial fibrosis for detecting early cardiac involvement.

Galectin-3 (Gal-3) is a beta-galactoside-binding lectin shown to be, in experimental studies, a mediator of cardiac fibrosis $[4,5]$ and upregulated in animal models of decompensated heart failure, as reviewed by de Boer et al. [6]. We previously demonstrated that Gal-3 is upregulated in the hearts of mice chronically infected with Trypanosoma cruzi [7]. Gal-3 may promote fibrosis through the activation of fibroblasts and macrophages, which is a hallmark of cardiac remodeling processes [8]. Current data suggest that Gal-3 secreted by activated macrophages acts on fibroblasts, establishing a link between inflammation and fibrosis [9]. In addition to the involvement in heart diseases, Gal-3 may be involved in other disease settings, such as cancer, liver disease, renal disease and various rheumatologic conditions [10-13]. Moreover, circulating Gal-3 has been found to be elevated in different human diseases associated with fibrosis [14-16]. A pathophysiological role for Gal-3 in heart failure was suggested by previous studies showing that Gal-3 infusion into murine pericardium induced adverse cardiac remodeling whereas coinfusion with a Gal-3 inhibitor counteracted these effects $[4,5]$.

Here we sought to examine the clinical correlation of plasma Gal-3 with myocardial fibrosis, in subjects with different forms of Chagas disease, using cardiac magnetic resonance imaging (MRI) as the gold standard method to estimate the percentage of myocardium affected by fibrosis.

\section{Methods}

\section{Study Population}

Subjects with Chagas disease were prospectively recruited between January 2012 and December 2013 in the Chagas disease outpatient clinic at Hospital São Rafael, a tertiary referral center located in Salvador, Bahia, Brazil.
Inclusion criteria were an age of 18-70 years and a diagnosis of Chagas disease confirmed by 2 positive serologic tests for antibodies against T. cruzi (indirect hemagglutination and indirect immunofluorescence). Exclusion criteria were: the acute form of Chagas disease, previous myocardial infarction or known coronary atherosclerotic disease (or $>2$ risk factors for it), primary valve disease, end-stage renal disease on dialysis, active hepatitis or cirrhosis, hematologic, neoplastic or bone diseases and contraindication to MRI.

We classified enrolled patients into 3 groups based on distinct stages of Chagas disease, according to the current Brazilian Chagas disease consensus [1], distributed as follows: (1) a group with the indeterminate form of the disease, comprising 17 asymptomatic subjects without signs of cardiac involvement characterized by normal electrocardiogram, chest X-ray and echocardiography, (2) a group with the cardiac form without ventricular dysfunction, comprising 16 consecutive subjects with known heart involvement defined as abnormal electrocardiogram (typically, right bundlebranch block with left anterior hemiblock) and without left ventricular dysfunction and (3) a group with the cardiac form with ventricular dysfunction, comprising 28 subjects with low left-ventricular ejection fraction, 16 of whom were in New York Heart Association (NYHA) class III/IV.

At the time of enrolment, all subjects underwent clinical assessments consisting of structured medical questionnaires, 12-lead electrocardiography, chest radiography, 24-hour ambulatory electrographic monitoring, exercise testing, conventional Doppler echocardiography and cardiovascular MRI.

The study complied with the Declaration of Helsinki, was approved by the Ethics Committee of the Hospital São Rafael and is registered in ClinicalTrials.gov under the identifier NCT01842854. All subjects signed a written informed consent before their inclusion in the study.

\section{Magnetic Resonance Imaging}

Cardiovascular MRI was performed using a Sigma HDx 1.5-T system (General Electric, Fairfield, Conn., USA). For assessment of the LV function, electrocardiography-gated, breath-hold, longaxis, short-axis and 4-chamber views were acquired at the same location in different sequences. Acquisition parameters used for the dynamic sequence included a repetition time (RT) of $3.5 \mathrm{~ms}$, an echo time (ET) of $1.5 \mathrm{~ms}$, a flip angle of $60^{\circ}$, a receiver bandwidth of $125 \mathrm{kHz}$, a $35 \times 35 \mathrm{~cm}$ field of view (FOV), a matrix of 256 $\times 148$, a temporal resolution (TR) of $35 \mathrm{~ms}$ and a slice thickness of $8.0 \mathrm{~mm}$ without gap.

Delayed enhancement (DE) images were acquired every heartbeat, 10-20 min after the administration of a gadolinium-based contrast $(0.1 \mathrm{mmol} / \mathrm{kg})$ using an RT of $7.1 \mathrm{~ms}$, an ET of $3.1 \mathrm{~ms}$, a flip angle of $20^{\circ}$, a first cardiac phase, $16 / 32$ views per segment, a matrix size of $256 \times 192$, a slice thickness of $8.0 \mathrm{~mm}$, a gap between slices of $2 \mathrm{~mm}$, a $32 \times 38 \mathrm{~cm} \mathrm{FOV}$, an inversion time of 150-300 $\mathrm{ms}$, a receiver bandwidth of $31.25 \mathrm{kHz}$ and 2 excitations. The myocardial DE technique was used to investigate myocardial fibrosis, which was estimated by a quantitative visual method.

\section{Gal-3 and NT-ProBNP}

Gal-3 and NT-proBNP concentrations were determined in EDTA plasma samples with the VIDAS ${ }^{\circledR}$ automated enzymelinked fluorescent assay (BioMérieux, Marcy-l'Étoile, France). The assay principle combines a one-step immunoassay sandwich
Noya-Rabelo et al. 
Table 1. Subjects' clinical and demographic characteristics

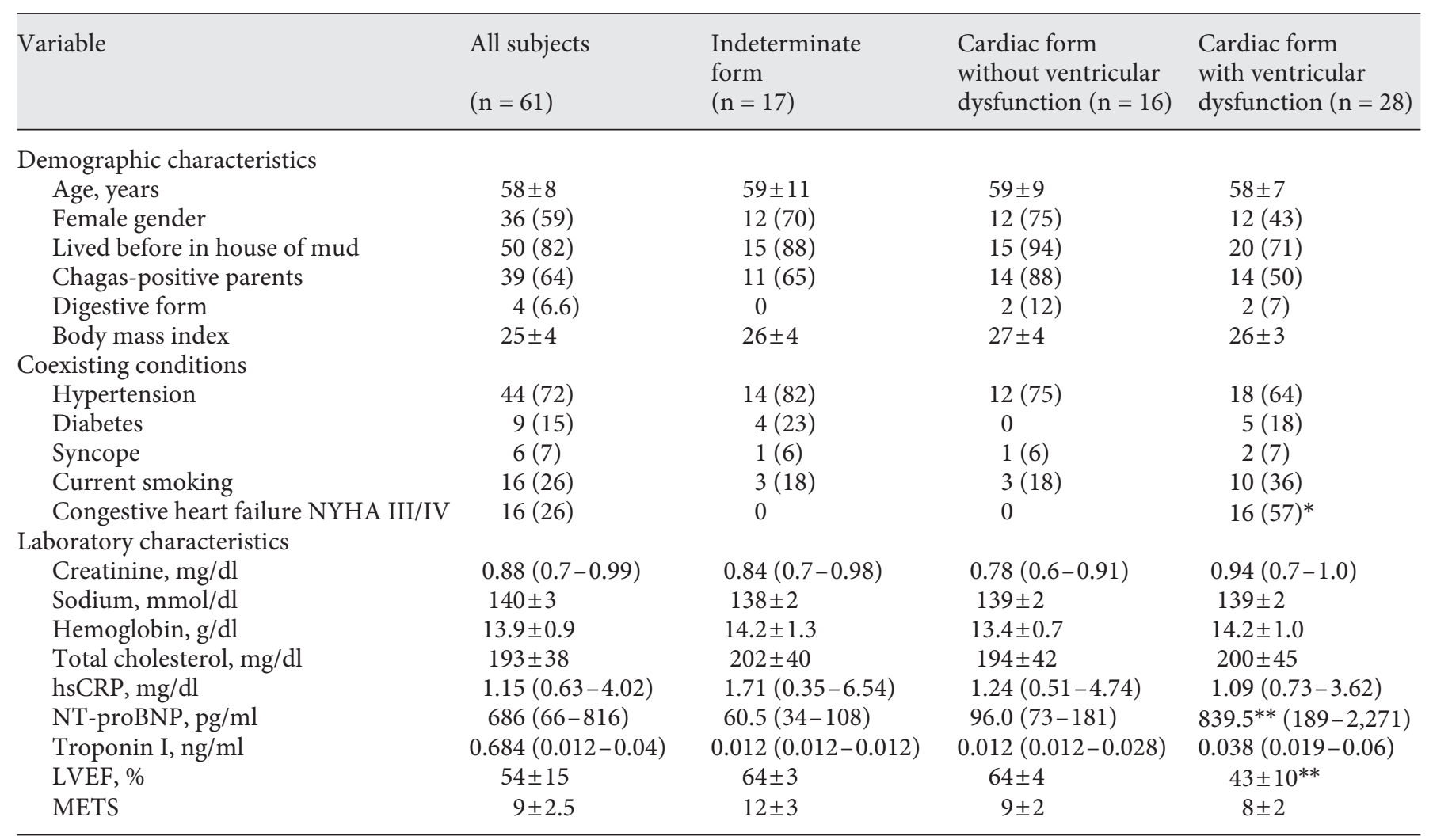

Data are expressed as mean $\pm \mathrm{SD}$ or $\mathrm{n}(\%)$ for discrete variables and median (IQI) for continuous nonnormal variables. LVEF $=\mathrm{LV}$ ejection fraction; METS $=$ metabolic equivalent of task; hsCRP $=$ high-sensitivy C-reactive protein. ${ }^{*} \mathrm{p}<0.001$, Fisher's exact test. ** $\mathrm{p}<0.001$, Kruskal-Wallis test, one-way ANOVA.

method with a final fluorescent detection (ELFA). The samples were transferred into the wells containing anti-Gal-3 or anti-NTproBNP antibodies conjugated with alkaline phosphatase. The intensity of the fluorescence is proportional to the concentration of antigens present in the sample. The measurement range was 3.3$100 \mathrm{ng} / \mathrm{l}$ for Gal-3 and 20-25.000 pg/ml for NT-proBNP.

\section{Sample Size Calculation}

Gal-3 concentration in patients with heart failure is described as $18.6 \pm 7.8 \mathrm{ng} / \mathrm{ml}$ [17]. The sample size was calculated for the comparison of the Gal-3 concentration between 2 groups of subjects defined by the presence of myocardial fibrosis assessed by MRI. Considering that subjects with myocardial fibrosis have values close to those described in heart failure patients $(18.6 \pm 7.8 \mathrm{ng} /$ $\mathrm{ml}$ ), we determined that the enrolment of 64 participants would provide a power of $80 \%$ to reject the null hypothesis if subjects without myocardial fibrosis had Gal-3 values 30\% lower than subjects with myocardial fibrosis, with the same standard deviation of $7.8 \mathrm{ng} / \mathrm{ml}$ for both groups, at a two-sided alpha level of 0.05 .

\section{Statistical Analysis}

Categorical variables are presented as numbers and percentages and continuous variables are presented as means (SD) or me- dian (interquartile interval, IQI). The significance of baseline differences was determined by the $\chi^{2}$ test, the Fisher exact test or the unpaired t test, as appropriate. Comparisons of continuous variables among groups were performed with an analysis of variance (ANOVA) test or the Kruskal-Wallis test, depending on normality assessed by the Shapiro-Wilk test. Correlation between continuous variables was evaluated by the Pearson or Spearman coefficient, depending on normality.

Analyses were performed using SPSS v20.0 (IBM), and a twosided $\mathrm{p}$ value $<0.05$ was considered to indicate statistical significance.

\section{Results}

\section{Baseline Characteristics}

We evaluated 61 subjects with Chagas disease, distributed as follow: 17 in group 1 (subjects with no evidence of cardiac involvement or heart failure), 16 in group 2 (cardiac form without ventricular dysfunction or symptoms) and 28 in group 3 (cardiac form with ventricular 
Table 2. Myocardial fibrosis on cardiac MRI

\begin{tabular}{|c|c|c|c|c|c|}
\hline & $\begin{array}{l}\text { All subjects } \\
(\mathrm{n}=61)\end{array}$ & $\begin{array}{l}\text { Indeterminate } \\
\text { form } \\
(\mathrm{n}=17)\end{array}$ & $\begin{array}{l}\text { Cardiac form } \\
\text { without ventricular } \\
\text { dysfunction }(n=16)\end{array}$ & $\begin{array}{l}\text { Cardiac form } \\
\text { with ventricular } \\
\text { dysfunction }(n=28)\end{array}$ & $\mathrm{p}$ value \\
\hline $\mathrm{DE}, \mathrm{n}(\%)$ & $35(57)$ & $6(35)$ & $7(44)$ & $22(79)$ & $0.001^{*}$ \\
\hline Myocardial fibrotic area, \% of LV mass (IQI) & $9.4(2.4-18.4)$ & $4.1(2.1-10.7)$ & $2.3(1.0-5.0)$ & $15.2(7.8-25)$ & $0.004^{* *}$ \\
\hline
\end{tabular}

* Fisher's exact test. ${ }^{* *}$ Kruskal-Wallis, one-way ANOVA.

Table 3. Myocardial fibrosis and subjects' clinical characteristics

\begin{tabular}{lccc}
\hline & With fibrosis & Without fibrosis & p value \\
\hline Age, years & $57 \pm 9.2$ & $58 \pm 7.6$ & 0.53 \\
Female gender & $16(43)$ & $18(86)$ & $0.002^{*}$ \\
Forms of the disease & $7(19)$ & $10(48)$ & $<0.001^{*}$ \\
$\quad$ Indeterminate & $7(19)$ & $9(43)$ & 0.67 \\
$\quad$ Cardiac without LV dysfunction & $23(62)$ & $2(9.5)$ & 0.01 \\
$\quad$ Cardiac with LV dysfunction & $11.8(9.1-12.6)$ & $13.7(9.2-14.2)$ & $0.002^{* *}$ \\
Gal-3, ng/ml & $211(96-1087)$ & $68(34-346)$ & 0.38 \\
NT-proBNP, pg/ml & $0.032(0.012-0.048)$ & $0.012(0.012-0.013)$ & $1.1(0.26-46.8)$ \\
Troponin I, ng/ml & $1.1(0.63-4.0)$ & & \\
hsCRP, mg/dl & &
\end{tabular}

Data are expressed as mean \pm SD or $\mathrm{n}(\%)$ for discrete variables and median (IQI) for continuous nonnormal variables. hsCRP $=$ High sensitivity C-reactive protein. * Fisher's exact test. ${ }^{* *}$ Mann-Whitney U test.

dysfunction, with or without symptoms). Mean age was $58 \pm 8.5$ years and $59 \%$ of the participants were women. The majority of subjects $(73.8 \%)$ were in NYHA functional class I or II and $4(6.6 \%)$ had concomitant gastrointestinal involvement. The prevalence of hypertension, diabetes, hypercholesterolemia and current smoking was similar across the 3 groups. As expected, higher NTproBNP values and a lower ejection fraction were observed in group $3(p<0.001)$. Ventricular tachycardia was detected in $20(33 \%)$ subjects on 24 -hour Holter monitoring (none from group 1, 5 from group 2 and 15 from group 3; $\mathrm{p}=0.001$ ). Clinical and demographic characteristics of the subjects are described in table 1 .

\section{Myocardial Fibrosis}

DE was identified in 37 of 61 subjects (64\%). The total amount of myocardial fibrosis was 9.4\% (IQI: 2.4-18.4) with a progressive increase across the different forms of the disease. Myocardial fibrosis was detected in 6 of 17 subjects in the indeterminate form (median 4.1\%, IQI: 2.1-10.7), 7 of 16 in the cardiac form without ventricular dysfunction (median 2.3\%, IQI: 1.0-5.0) and 22 of 28 subjects in the cardiac form with ventricular dysfunction (median 15.2\%, IQI: 7.8-25.0, $\mathrm{p}=0.001$ ). DE was detected more frequently in the inferolateral and apical segments of the left ventricle. Moreover, subjects with DE showed a lower ejection fraction ( $68 \pm 13$ vs. $48 \pm 18 \%$; $\mathrm{p}<0.001$ ), higher NT-proBNP values [197 pg/ml (IQI: $91-2,682$ ) vs. $73 \mathrm{pg} / \mathrm{ml}$ (IQI: $34-190) ; \mathrm{p}=0.01$; tables 2 , $3]$ and ventricular tachycardia detected on Holter monitoring ( 43 vs. $15 \%$; $\mathrm{p}=0.03$ ).

\section{Assessment of Gal-3}

The median concentration of Gal-3 in the study sample was $12.1 \mathrm{ng} / \mathrm{ml}$ (IQI: 9.4-14.4). No differences were observed in Gal-3 concentration according to the presence or absence of myocardial fibrosis, with a median Gal-3 concentration of $11.7 \mathrm{ng} / \mathrm{ml}$ (IQI: 9.4-15) in subjects with DE versus $12.9 \mathrm{ng} / \mathrm{m}$ (IQI: 9.2-14) in subjects without $\mathrm{DE}$ ( $\mathrm{p}=0.67$; fig. 1$)$. No correlation was found between myocardial fibrosis and Gal-3 concentration $(r=0.098 ; p=0.47$; fig. 2). 


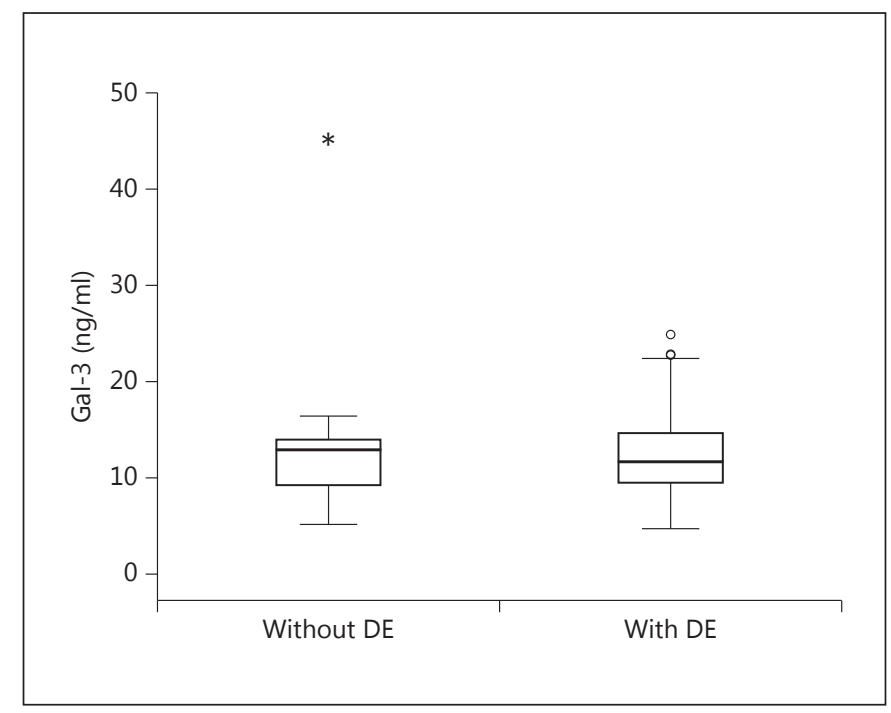

Fig. 1. Plasmatic concentration of Gal-3 assessed by ELISA in subjects with and without DE detected by MRI (Mann-Whitney U test, $\mathrm{p}=0.67$ ).

Higher values of Gal-3 were found in women compared to men, with median Gal-3 concentrations of 13.4 $\mathrm{ng} / \mathrm{ml}$ (IQI: $10.3-15.1$ ) and $10.4 \mathrm{ng} / \mathrm{ml}$ (IQI: 8.9-10.1, p = $0.03)$, respectively. However, no differences were identified in subjects with a lower ejection fraction $(\mathrm{p}=0.45)$, higher NT-proBNP values $(\mathrm{p}=0.26)$, greater age $(\mathrm{p}=$ $0.15)$, higher troponin $(p=0.26)$ and high-sensitivity $C$ reactive protein values $(\mathrm{p}=0.86)$. Additionally, we did not identify differences in Gal-3 concentration comparing groups of patients with different forms of Chagas disease, with a median concentration of $12.1 \mathrm{ng} / \mathrm{ml}$ (IQI: 8.8-18.3) in group $1,12.1 \mathrm{ng} / \mathrm{ml}$ (IQI: 10.1-13.9) in group 2 and $12.0 \mathrm{ng} / \mathrm{ml}$ (IQI: $11.0-14.8$ ) in group 3 ( $\mathrm{p}=0.90$; fig. 3).

\section{Discussion}

A useful biomarker must have a diagnostic or prognostic value or aid therapeutic guidance. Gal-3 has been shown to mediate fibrosis in several disease settings, including cardiac diseases. In animal models, Gal-3 mediates ventricular remodeling, and the administration of Gal-3 leads to a phenotype of progressive fibrosis and LV systolic dysfunction [4]. These observations have led to an increasing interest in Gal-3 as a potential heart failure biomarker that could reflect ongoing ventricular remodeling and progressive fibrosis.

Gal-3 in Chagas Cardiomyopathy

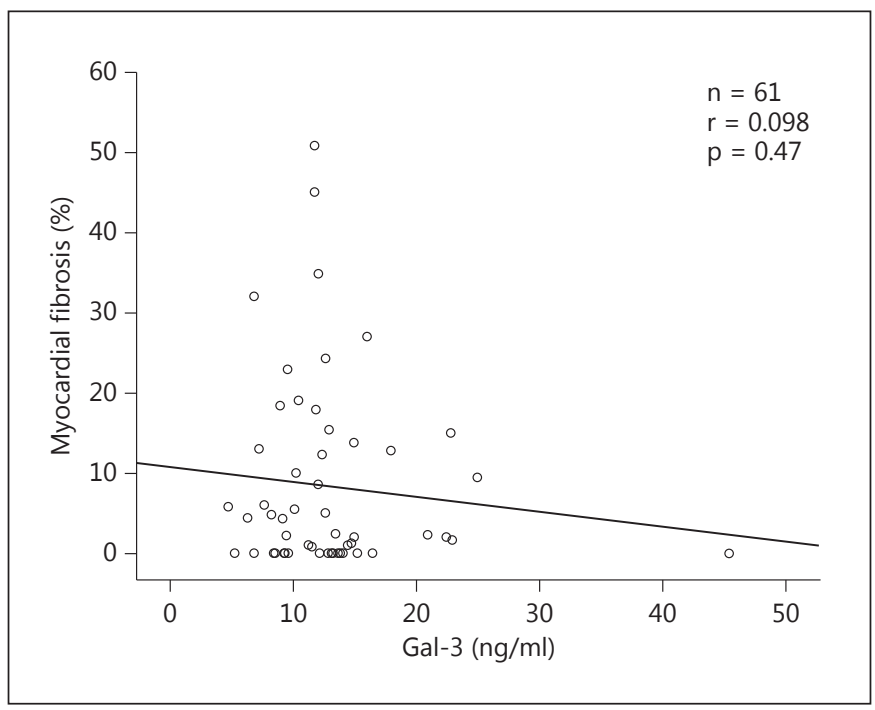

Fig. 2. Correlation between plasmatic concentration of Gal-3 and percentage of myocardial fibrosis assessed by cardiovascular MRI (Spearman's correlation, $\mathrm{r}=0.098, \mathrm{p}=0.47$ ).

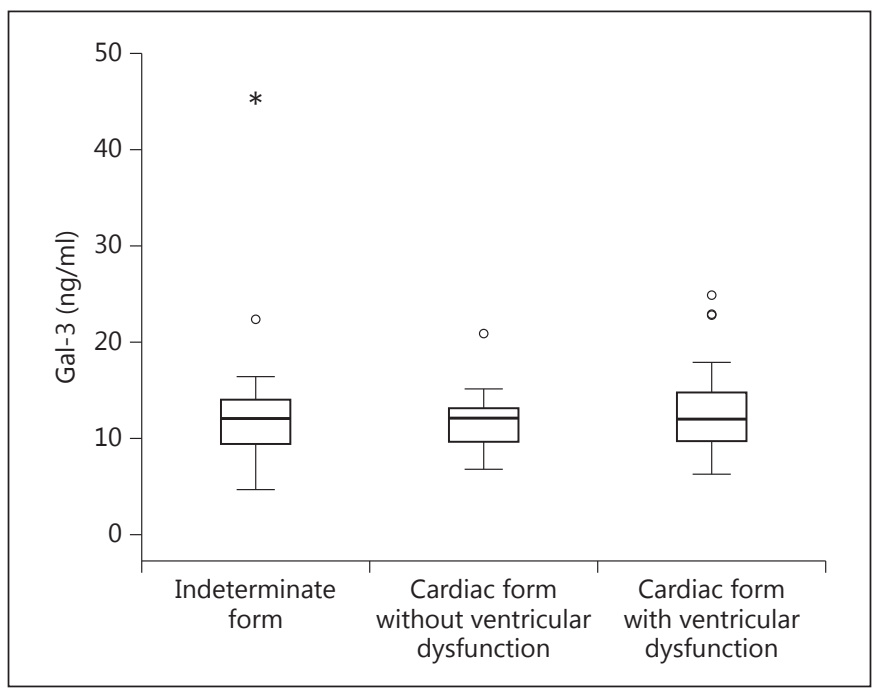

Fig. 3. Plasmatic concentration of Gal-3 assessed by ELISA in subjects with different forms of Chagas disease (Kruskal-Wallis, oneway ANOVA, $\mathrm{p}=0.90)$.

This study provides the first evaluation of the Gal-3 role as a biomarker in a population with Chagas disease. Despite the experimental data on mice indicating a correlation between Gal-3 expression and the progression of Chagas disease $[7,18]$, our analysis in the clinical setting showed no direct relationship between the amount of myocardial fibrosis and the plasmatic concentration of 
Gal-3. In contrast, Lepojärvi et al. [19] demonstrated a positive correlation between myocardial fibrosis and the serum concentration of Gal-3, although their data were obtained from a different population which included subjects with coronary artery disease and preserved LV function. Likewise, in patients with nonischemic dilated cardiomyopathy, Gal-3 is able to predict myocardial fibrosis as DE on cardiovascular MRI [20].

Although the median percentage of fibrosis varied across the different clinical forms of Chagas disease, the median concentration of Gal-3 was nearly identical in all 3 groups. Subjects with the cardiac form and ventricular dysfunction had a higher percentage of myocardial fibrosis than subjects without cardiac involvement, but the concentration of Gal-3 was not significantly different. Nonetheless, our data regarding the higher concentration of Gal-3 in females are in agreement with previously published data. Ho et al. [21] also demonstrated that Gal-3 concentration was significantly higher in women (median: $14.3 \mathrm{ng} / \mathrm{ml}$ ) compared with men (median: $13.1 \mathrm{ng} / \mathrm{ml}$, $\mathrm{p}<0.05$ ). Likewise, Daniels et al. [22] found that the concentration of Gal-3 was higher in women [15.3 (12.1$19.8)$ vs. 13.7 (10.7-17.4) ng/ml, p < 0.0001].

The role of circulating Gal-3 as a biomarker in heart failure of different etiologies has been supported by studies that showed that an elevated Gal-3 concentration, after adjusting for other variables, is associated with poorer outcomes in subjects with heart failure [23,24]. However, these studies have limitations regarding their sample size or the number and type of variables included in their models for multivariate analysis. In contrast, the findings of Felker et al. [25], who included a larger cohort, showed that, after adjusting for more clinical variables (including NT-proBNP), Gal-3 was no longer able to significantly predict outcome in subjects with heart failure. Moreover, Srivatsan et al. [26], in a recent systematic review, found
Gal-3 to be ineffective in the prediction of mortality when variables such as estimated glomerular filtration rate, $\mathrm{LV}$ ejection fraction and NT-proBNP were considered in the analysis.

There are several limitations to this study that may affect the interpretation of its results. First, it was conducted at a single tertiary and academic hospital, with a small sample size. However, there are also advantages to a single-center location, including the possibility of following all subjects closely for the duration of the study and gathering considerably detailed information on each study participant. The second limitation is that we measured Gal-3 at a single time point, which could not supply information about its importance over time. Lastly, the circulating concentration of Gal-3 may not accurately reflect the expression in the heart tissue.

\section{Conclusion}

That there is a lack of correlation between the degree of myocardial fibrosis and the plasma concentration of Gal-3, therefore refuting the hypothesis of a predictive role of this molecule as a biomarker for myocardial fibrosis in subjects with Chagas disease.

\section{Acknowledgements}

The authors wish to acknowledge BioMérieux for supplying VIDAS kits for the NT-proBNP and Gal-3 assessments. This work was financially supported by FAPESB.

\section{Conflict of Interest}

There were no conflicts of interest.

\section{References}

1 Andrade J, Marin-Neto J, Paola A, Vilas-Boas F, Oliveira G, Bacal F, et al; Sociedade Brasileira de Cardiologia: I. Latin American guidelines for the diagnosis and treatment of Chagas cardiomyopathy (in Portuguese). Arq Bras Cardiol 2011;97:1-48.

2 Barbosa AP, Cardinalli Neto A, Otaviano AP, Rocha BF, Bestetti RB: Comparison of outcome between Chagas cardiomyopathy and idiopathic dilated cardiomyopathy. Arq Bras Cardiol 2011;97:517-525.
3 Rassi A Jr, Rassi A, Marin-Neto JA: Chagas heart disease: pathophysiologic mechanisms, prognostic factors and risk stratification. Mem Inst Oswaldo Cruz 2009;104(suppl 1):152-158.

4 Sharma UC, Pokharel S, van Brakel TJ, van Berlo JH, Cleutjens JP, Schroen B, André S, Crijns HJ, Gabius HJ, Maessen J, Pinto YM: Galectin-3 marks activated macrophages in failure-prone hypertrophied hearts and contributes to cardiac dysfunction. Circulation 2004; 110:3121-3128.
5 Liu YH, D’Ambrosio M, Liao TD, Peng H, Rhaleb NE, Sharma U, André S, Gabius HJ, Carretero OA: N-Acetyl-seryl-aspartyl-lysyl-proline prevents cardiac remodeling and dysfunction induced by galectin-3, a mammalian adhesion/growth-regulatory lectin. Am J Physiol Heart Circ Physiol 2009;296:H404H412.

6 de Boer RA, Yu L, van Veldhuisen DJ: Galectin-3 in cardiac remodeling and heart failure. Curr Heart Fail Rep 2010;7:1-8. 
7 Soares MB, Lima RS, Souza BS, Vasconcelos JF, Rocha LL, Dos Santos RR, Iacobas S, Goldenberg RC, Lisanti MP, Iacobas DA, et al: Reversion of gene expression alterations in hearts of mice with chronic chagasic cardiomyopathy after transplantation of bone marrow cells. Cell Cycle 2011;10:1448-1455.

8 Sutton MG, Sharpe N: Left ventricular remodeling after myocardial infarction: pathophysiology and therapy. Circulation 2000; 101:2981-2988.

9 Henderson NC, Mackinnon AC, Farnworth SL, Kipari T, Haslett C, Iredale JP, Liu FT, Hughes J, Sethi T: Galectin-3 expression and secretion links macrophages to the promotion of renal fibrosis. Am J Pathol 2008;172: 288-298.

10 Funasaka T, Raz A, Nangia-Makker P: Galectin-3 in angiogenesis and metastasis. Glycobiology 2014;24:886-891.

11 de Oliveira SA, de Freitas Souza BS, Sá Barreto EP, Kaneto CM, Neto HA, Azevedo CM, Guimarães ET, de Freitas LA, Ribeiro-DosSantos R, Soares MB: Reduction of galectin-3 expression and liver fibrosis after cell therapy in a mouse model of cirrhosis. Cytotherapy 2012;14:339-349.

12 Kolatsi-Joannou M, Price KL, Winyard PJ, Long DA: Modified citrus pectin reduces galectin-3 expression and disease severity in experimental acute kidney injury. PLoS One 2011;6:e18683.

13 de Oliveira FL, Gatto M, Bassi N, Luisetto R, Ghirardello A, Punzi L, Doria A: Galectin-3 in autoimmunity and autoimmune diseases. Exp Biol Med (Maywood) 2015;240:10191028.
14 de Boer RA, Voors AA, Muntendam P, van Gilst WH, van Veldhuisen DJ: Galectin-3: a novel mediator of heart failure development and progression. Eur J Heart Fail 2009;11: 811-817.

15 Nishi Y, Sano H, Kawashima T, Okada T, Kuroda T, Kikkawa K, Kawashima S, Tanabe M, Goto T, Matsuzawa Y, et al: Role of galectin-3 in human pulmonary fibrosis. Allergol Int 2007;56:57-65.

16 Taniguchi T, Asano Y, Akamata K, Noda S, Masui Y, Yamada D, Takahashi T, Ichimura Y, Toyama T, Tamaki Z, et al: Serum levels of galectin-3: possible association with fibrosis, aberrant angiogenesis, and immune activation in patients with systemic sclerosis. J Rheumatol 2012;39:539-544.

17 Lok DJ, Van Der Meer P, de la Porte PW, Lipsic E, Van Wijngaarden J, Hillege HL, van Veldhuisen DJ: Prognostic value of galectin-3, a novel marker of fibrosis, in patients with chronic heart failure: data from the DEAL-HF study. Clin Res Cardiol 2010;99: 323-328.

18 Pineda MA, Cuervo H, Fresno M, Soto M, Bonay P: Lack of galectin-3 prevents cardiac fibrosis and effective immune responses in a murine model of Trypanosoma cruzi infection. J Infect Dis 2015;212:1160-1171.

19 Lepojärvi ES, Piira OP, Pääkkö E, Lammentausta E, Risteli J, Miettinen JA, Perkiömäki JS, Huikuri HV, Junttila MJ: Serum PINP, PIIINP, galectin-3, and ST2 as surrogates of myocardial fibrosis and echocardiographic left ventricular diastolic filling properties. Front Physiol 2015;6:200.
20 Vergaro G, Del Franco A, Giannoni A, Prontera C, Ripoli A, Barison A, Masci PG, Aquaro GD, Cohen Solal A, Padeletti L, et al: Galectin-3 and myocardial fibrosis in nonischemic dilated cardiomyopathy. Int J Cardiol 2015;184:96-100.

21 Ho JE, Liu C, Lyass A, Courchesne P, Pencina MJ, Vasan RS, Larson MG, Levy D: Galectin-3, a marker of cardiac fibrosis, predicts incident heart failure in the community. J Am Coll Cardiol 2012;60:1249-1256.

22 Daniels LB, Clopton P, Laughlin GA, Maisel AS, Barrett-Connor E: Galectin-3 is independently associated with cardiovascular mortality in community-dwelling older adults without known cardiovascular disease: the Rancho Bernardo Study. Am Heart J 2014;167: 674-682.e671.

23 Shah RV, Chen-Tournoux AA, Picard $\mathrm{MH}$, van Kimmenade RR, Januzzi JL: Galectin-3, cardiac structure and function, and long-term mortality in patients with acutely decompensated heart failure. Eur J Heart Fail 2010;12: 826-832.

24 Toprak G, Yüksel H, Demirpençe Ö, Islamoglu Y, Evliyaoglu O, Mete N: Fibrosis in heart failure subtypes. Eur Rev Med Pharmacol Sci 2013;17:2302-2309.

25 Felker GM, Fiuzat M, Shaw LK, Clare R, Whellan DJ, Bettari L, Shirolkar SC, Donahue M, Kitzman DW, Zannad F, et al: Galectin-3 in ambulatory patients with heart failure: results from the HF-ACTION study. Circ Heart Fail 2012;5:72-78.

26 Srivatsan V, George M, Shanmugam E: Utility of galectin-3 as a prognostic biomarker in heart failure: where do we stand? Eur J Prev Cardiol 2015;22:1096-1110. 